\title{
In Vitro Antioxidant Activity of Melastomastrum capitatum (Vahl) A. \& R. Fern. (Melastomataceae) Leaf Methanol Extractby DPPH Radical Scavenging Activity
}

\author{
Ukwubile Cletus A.
}

Department of Science Laboratory Technology, Biology Unit, Federal Polytechnic Bali, Nigeria

\begin{abstract}
Antioxidant activity of methanol extract of Melastomastrumcapitatum leaf was evaluated using DPPH antioxidant assay. The methanol extract of the plant showed potent radical cat ion scavenging activity. The maximum inhibitory concentration $\left(I C_{50}\right)$ and radical cat ion scavenging activity of the plant was found to increase in concentration dependent fashion from 100, 200, 300, 400 and $500 \mu \mathrm{g} / \mathrm{mL}$. This study indicates significant free radical scavenging potential of the plant of $M$. capitatumwhich can be exploited for the treatment of various free radical mediated ailments like cancers and tumours.
\end{abstract}

Keywords: In vitro, Antioxidant activity, Melastomastrumcapitatum, DPPH scavenging.

\section{INTRODUCTION}

Antioxidants are substances which are used as foods or as additives to foods whether in smaller amount or bigger amount, which are capable of preventing the oxidation of oxidizing agents which are capable of releasing free oxygen radials in the body [1]. These substances have the potentials to inhibit specific oxidizing enzymes that can react with oxygen radicals, thereby causing damage to molecule in humancells [2].

Antioxidants act in the body in various ways by; reducing localized oxygen concentration, preventing the commencement of chain by scavenging radicals, breaking down lipid peroxides to peroxyl and alkoxyl radicals, reducing peroxides by converting them to non- radicals product, and breaking chain to prevent hydrogen reduction [3]. Currently, due to high toxicity of synthetic antioxidants, natural antioxidants of plant origin have gained popularity among natural product researchers.

Melastomastrum capitatum is a dicot plant belonging to the family Melastomataceae. It is locally called 'Belkon"' in Fulani language in Nigeria's North-East, Taraba State. Anti-inflammatory and analgesic activity as well as anti-hyper-cholesterolemic activities of the leaf methanol extract in albino mice has been reported by Ukwubile et al. [4]. The crude leaf methanol extract contains mainly glycosides, alkaloids, tannins and carbohydrates. In traditional medicine, the plant is used as antirheumatic agents, to treat stomach ache, for blood purification, for treating diuresis, for correcting intestinal and pulmonary problems [4].

This present study was carried out to evaluate the antioxidant activity of $M$. capitatum leaf methanol extract in vitro by DPPH scavenging radical assay.

\section{MATERIALS AND MeTHODS}

\subsection{Materials}

DPPH, air dried leaves of Melastomastrum capitatum, ascorbic acid, beaker, micro pipette, distilled water, micro cuvette, test tube rack, test tube, spatula, UV/VIS spectrophotometer, ATI CO ${ }^{\mathrm{TM}}$ Model, methanol, filter paper, Kim white, mortar and pestle, measuring cylinder, separating funnel, etc.

\subsection{Methods}

\subsubsection{Collection and Identification of Plant}

Fresh leaves of Melastomastrum capitatumwere collected in the evening hour from Mambila Plateau Sardauna Local Government Area Taraba State, and was authenticated by Mr. Cletus A. Ukwubile 
(Biology Unit) of the Department of Science Laboratory Technology. A plant press was prepared and was deposited with voucher number "MELA001"' in the herbarium of Biology Unit of Science Laboratory Technology Department, Federal Polytechnic, Bali, Nigeria.

\subsubsection{Preparation and Extraction of Plant Material}

The leaves of Melastomastrum capitatum, were air-dried at room temperature $\left(40^{\circ} \mathrm{C}\right)$ for two weeks and was reduced into fine powder using electronic blender. $600 \mathrm{~g}$ of the powder was defatted in 700 $\mathrm{mL}$ petroleum ether and then extracted with separating funnel by cold maceration techniques. The extract was then filtered using Whatman No 1 filter paper. The filtrate was concentrated, in vacuo at room temperature. After this, the methanol extract was further partitioned successively using solvents in increasing order of polarity from the eluotropicseries in this other: carbon tetrachloride, chloroform, acetone, ethyl acetate and methanol. The final weight of the methanol leaf extract was calculated from the formula below:

$$
\% \text { yield }=(\text { Final weight of powder/initial weight of powder }) \mathrm{X} 100 .
$$

\subsubsection{Antioxidant and Free Radicals Scavenging Assay}

The method of Brain-Williamset al. [7] was used in a methanol solution of 2, 2- diphenyl-picrylhydrazyl (DPPH) radicals (concentration $1.0 \times 10^{-4} \mathrm{~m}$ ). The test extract was added in concentrations of $100,200,300,400$ and $500 \mu \mathrm{g} / \mathrm{mL}$. The reaction mixture was shaken vigorously and kept in the dark for $30 \mathrm{~min}$. The absorbance of the solution were measured using $\mathrm{ATICO}^{\mathrm{TM}}$ Model UV-Vis spectrophotometer at $546.0 \mathrm{~nm}$ wavelength against a blank without DPPH. Decreasing of DPPH solution absorbance indicated potential scavenging activity while the increase was given as DPPH radical scavenging activity. This activity is given as \% DPPH radical scavenging activity that is calculated in the equation below:

$\%$ DPPH radical scavenging $=\underline{\text { Sample absorbance }} \times 100$

\section{Control absorbance}

DPPH solution without sample solution was use as control. All tests were run in triplicate and average. Ascorbic acid was use as reference drug [5-8].

\section{RESULTS AND DISCUSSION}

The DPPH analysis (\% scavenge) showed a higher percentage of radical sequestration with statistical difference. In the concentration of $100 \mu \mathrm{g} / \mathrm{mL}$, the DPPH scavenge, showed a higher concentration of $91.70 \pm 14.63$ and at the concentration of $500 \mu \mathrm{g} / \mathrm{mL}$, the DPPH scavenge was $25.90 \pm 1.97$, which means that the lower the concentration $100 \mathrm{ug} / \mathrm{mL}$ the higher the DPPH scavenging $(91.70 \pm 14.63)$, and the higher the concentration $(500 \mathrm{ug} / \mathrm{mL})$ the lower the DPPH scavenging $(25.90 \pm 1.97)$ of the plant extract. The inhibitory concentration showed that the lower the concentration $(54.2 \%)$. At the concentration of $500 \mathrm{ug} / \mathrm{mL}$, the inhibitory concentration was $87.1 \%$. The antioxidant activity of $M$. capitatum revealed that the plant showed higher antioxidant activity at a higher concentration (Table 1).

The presence of non-antioxidant food component (amino acid and uronic acid) may interfere in the quantification of antioxidant activity in food [9]. Studying the antioxidant capacity of catching and Gallic acid, using DPPH with different solvents (water, methanol/water, methanol acetone/water) found different among the method. However the DPPH assays did not demonstrated any interference due to solvent polarity. Begetti et al. [9] quantified the antioxidant activity of M.capitatum, which showed high antioxidant activity for the DPPH method as demonstrated by the leaf extracts. Total phenol have antioxidant activity, acting in the neutralization of free radicals, and contributing to the control of oxidative stress in pancreatic islets of cancer mice. The result regarding antioxidant activity showed that methanol extract of $M$. capitatum has strong antioxidant activity suggesting antioxidant property, as demonstrated by the in vitro study [10].

Table1. Antioxidant activity of Melastomastrum capitatummethanol leaf extract

\begin{tabular}{|l|l|l|}
\hline Conc. $(\boldsymbol{\mu g} / \mathbf{m L})$ & DPPH Scavenging $(\mathbf{n m})$ & $\mathbf{I ~ C}_{\mathbf{5 0}}(\mathbf{\%})$ \\
\hline Control & $200 \pm 7.49$ & - \\
\hline 100 & $91.70 \pm 1.61$ & 54.2 \\
\hline 200 & $70.40 \pm 1.14$ & 64.8 \\
\hline 300 & $64.40 \pm 1.72$ & 67.8 \\
\hline 400 & $63.80 \pm 1.75$ & 68.1 \\
\hline 500 & $25.90 \pm 1.97$ & 87.1 \\
\hline
\end{tabular}

Abs (546 nm), ascorbic acid is the reference drug

International Journal of Medicinal Plants and Natural Products (IJMPNP) 


\section{CONCLUSION}

The study showed that methanol leaf extract of $M$. capitatum has a higher antioxidant activity. It is possible that the presence of major compounds found in these extract reported (ellagic acid, gallic acid and rutin) by previous researchers, might have contributed to the antioxidant effect of the extract. Overall, the result are very promising and may demonstrate the action of compound present in $M$. capitatum leaf with antioxidant property.

However, despite the antioxidant property found during this study, further study are necessary to determine the respond of methanol leaf extract, and the antioxidant signaling process of organs responsible for this, which will consolidate the results for future drug development.

\section{ACKNOWLEDGEMENT}

The author is thankful to Mr. Godfrey Victor for his assistance in plant collection and preparation for extraction.

\section{REFERENCES}

[1] Al-salih, R.M. (2010). Clinical Experimental Evidence: Synergistic Effect of Gallic Acid and Tannic Acid as Anti-diabetic and Antioxidant agents; 4: 109-119.

[2] Benzie, S.E., Strain,J.J. (1996). The ferric reducing ability of plasma (FRAP) as a measure of "Antioxidant Power": The FRAP assay. Anal of. Biochemistry; 239: 70-76.

[3] Nenadis, N., Wang, L.F., Tsimidou, M., Zhang, H.Y.(2004). Estimation of scavenging activity of phenolic compound using the ABTS assay. Journal of Agric. Food chem. 52: 4669-4674.

[4] Ukwubile, C.A., Agu, M.O., Agabila, E. J. (2015). Phytochemical screening and acute toxicity study of M. capitatum leaf extract. International Journal of Biological chemistry; 3(2): 56-61.

[5] Halliwell, B., Aeschbach, R., Loliger, J., Aruoma, O.I. (1995). The characterization of Antioxidant. Food and chemical. Toxicology; 33: 601-617.

[6] Larrauri, J., Reperez, P., Saura, C.F. (1997). Mango peel fibers with antioxidant activity. Journal of Food Science; 205: 29-42.

[7] Perez-Jimenez, J., Calixto, F.S. (2006). Effect of solvent and certain food constituents on different antioxidant capacity assays. Food Res. Int. 39: 791-800.

[8] Temple, N.J. (2001). Antioxidant and disease: More question than answers. Nutritional Research; 20: 449-459.

[9] Bergetti, M., Facco, E.M.P., Piccolo, J., Hirsch, G.E., Rodriguez Yamaha, D., Kobori, C.N. (2011). Physicochemical characterization of peppermint. International Journal of Plant Products; 31: 141-154.

[10] Coloma, T.C., Figueiredo, D., Jcazarin, C.B., Schumacher, N.S.G., Marostica, M.R., Jr., Meletti, L.M., (2013). Antioxidant and anti-diabetic potential of Passiflora alatacurtis methanol leaf extract in type 1 diabetes mellitus (NOD-mice). International Journal of Immuno-pharmacology; 18: 106-115. 